\title{
Journal of the Society for Gynecologic Investigation
} \section{Women Receiving Prophylactic Antithrombotic Medication L. H. Peeters \\ Journal of the Society for Gynecologic Investigation 2005 12: 112 \\ DOI: 10.1016/j.jsgi.2004.10.009 \\ The online version of this article can be found at: \\ http://rsx.sagepub.com/content/12/2/112}

Pre-pregnant Prediction of Recurrent Preeclampsia in Normotensive Thrombophilic Formerly Preeclamptic

Marc E. A. Spaanderman, Robert Aardenburg, Timo H. A. Ekhart, Hugo W. F. van Eyndhoven, Peter W. de Leeuw and Louis

\author{
Published by: \\ (S)SAGE \\ http://www.sagepublications.com \\ On behalf of:

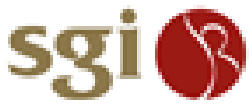 \\ Society for Gynecologic Investigation
}

Additional services and information for Journal of the Society for Gynecologic Investigation can be found at:

Email Alerts: http://rsx.sagepub.com/cgi/alerts

Subscriptions: http://rsx.sagepub.com/subscriptions

Reprints: http://www.sagepub.com/journalsReprints.nav

Permissions: http://www.sagepub.com/journalsPermissions.nav

Citations: http://rsx.sagepub.com/content/12/2/112.refs.html

>> Version of Record - Feb 1, 2005

What is This? 


\title{
Pre-pregnant Prediction of Recurrent Preeclampsia in Normotensive Thrombophilic Formerly Preeclamptic Women Receiving Prophylactic Antithrombotic Medication
}

\author{
Marc E. A. Spaanderman, MD, PhD, Robert Aardenburg, MD, \\ Timo H. A. Ekhart, BSc, Hugo W. F. van Eyndhoven, MD, \\ Peter W. de Leeuw, MD, PhD, and Louis L. H. Peeters, MD, PhD
}

\begin{abstract}
BACKGROUND: Both hemodynamic abnormalities and thrombophilia predispose to pregnancy-associated vascular complications such as fetal growth restriction, stillbirth, preeclampsia, and placental abruption. Antithrombotic treatment may reduce the risk for these events. In this study we tested the hypothesis that in normotensive thrombophilic formerly preeclamptic women certain alterations in hemodynamic function as measured under nonpregnant conditions predict the development of hypertensive disorders and/or fetal growth restriction in the subsequent pregnancy.

METHODS: In 350 nondiabetic formerly preedamptic women, we measured in the follicular phase of the menstrual cycle at least 5 months postpartum central hemodynamic, metabolic, and hemostatic variables. In the subsequent ongoing pregnancy we determined fetal outcome variables and the incidence of maternal vascular complications. In addition to a normotensive thrombophilic profile, inclusion for final analysis required a subsequent singleton pregnancy, established within 1 year following the pre-pregnant evaluation and ongoing beyond 16 weeks' gestation. As a consequence, 47 normotensive thrombophilic formerly preeclamptic women could be included for final analysis. All formerly preedamptic participants received aspirin throughout pregnancy. Additionally, those with thrombophilia or hyperhomocysteinemia were treated with low molecular weight heparin and with pyridoxine and folic acid supplementation, respectively.

Results: Among 350 formerly preeclamptic women, 266 (76\%) were normotensive and 84 (24\%) hypertensive. About half (140/266) of normotensive formerly preedamptic participants were thrombophilic. One hundred eighteen formerly preeclamptic participants succeeded in establishing an ongoing pregnancy within 1 year. From this subset of formerly preedamptic women, 47 were normotensive thrombophilic; 23 remained normotensive (THROMB), whereas 24 developed at least gestational hypertension (COMPLITHROMB). Participants in the latter subgroup were more obese than those remaining normotensive. In addition, this former subset of women had a higher vascular resistance index, and a lower plasma volume and cardiac index. With respect to fetal outcome, COMPLITHROMB gave birth to an infant with a lower birth weight relative to THROMB. Preedampsia with or without the hemolysis, elevated liver enzymes, and low platelets (HELLP) syndrome recurred in $26 \%$ of the participants in the whole thrombophilic group, in which a low pre-pregnant plasma volume and a raised vascular resistance predisposed for recurrent hypertensive disorders.

CONCLUSION: Pre-pregnant hemodynamic, metabolic, and clotting variables in formerly preeclamptic women can predict hypertension in the subsequent pregnancy. (J Soc Gynecol Investig 2005;12: 112-7) Copyright (C) 2005 by the Society for Gynecologic Investigation.
\end{abstract}

KeY wORDS: Preeclampsia, plasma volume, recurrence, pre-pregnant, prediction, thrombophilia.

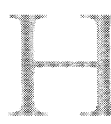
igh blood pressure complicates almost $10 \%$ of all pregnancies. ${ }^{1,2}$ It is an important cause of perinatal mortality and morbidity, as it predisposes for fetal growth restriction and iatrogenic preterm birth. In recent

From the Department of Obstetrics and Gynecology, University Medical Center Nijmegen St. Radboud, Nijmegen; and Department of Obstetrics and Gynecology and Department of Internal Medicine, Academic Hospital Maastricht, Maastricht, The Netherlands.

Address correspondence and reprint requests to: Marc E. A. Spaanderman, MD, PhD, Department of Obstetrics and Gynecology, UMCN St. Radboud, P.O. Box 9101, Room 2.274, 6500 HB Nijmegen, The Netherlands. E-mail: m.spaanderman@obgyn.umcn.nl

Copyright $(2005$ by the Society for Gynecologic Investigation. Published by Elsevier Inc. years, evidence is accumulating that particularly preexisting vascular, metabolic, or clotting disorders predispose to hypertensive complications in pregnancy. ${ }^{3-8}$ The latter suggests that in these cases the preexistent disorder predisposes for "endothelial decompensation" in pregnancy, the common end point of different pathogenetic pathways in pregnancy-related hypertensive syndromes. ${ }^{9}$ Recently, we observed in formerly preeclamptic women that a low plasma volume prior to pregnancy predisposes to recurrence of a hypertensive disorder in a next pregnancy. ${ }^{8}$ Unfortunately, the predictive value of a 
subnormal plasma volume was modest, probably because gestational vascular complications may result from a wide variety of hemodynamic, clotting, and mixed disorders. The latter indicates that in formerly preeclamptic women, stratification for potential underlying pathophysiologically distinct disorders may improve the value of subnormal plasma volume and that of other markers in predicting recurrence of hypertensive disease and/or placental insufficiency in a next pregnancy.

Thrombophilia, a condition that predisposes to thromboembolic disease, is associated with an increased risk for hypertensive complications in pregnancy, including placental insufficiency. ${ }^{3-6,10}$ Although antithrombotic prophylaxis in these women may reduce the risk to develop these complications, it is unlikely to ameliorate concomitant nonthrombotic risk conditions. ${ }^{11}$

Taking a preexistent risk condition as a starting point, ${ }^{6}$ the following questions may be addressed: First, what is the recurrence rate of hypertensive complications in a subsequent pregnancy for certain identifiable risk conditions? Second, is the presence of more than one disorder associated with a higher recurrence rate of hypertensive complications in pregnancy?

The objective of the present study was to test the hypothesis that in normotensive thrombophilic formerly preeclamptic women, hemodynamic, metabolic, and volume variables determined before pregnancy are clinically relevant for predicting recurrent hypertensive disorders and/or fetal growth restriction in a next pregnancy. To this end, we determined in formerly preeclamptic women, clotting function, central hemodynamic variables, and plasma volume before the next pregnancy. Then, we registered the recurrence rate of hypertensive complications and/or fetal growth restriction in that next pregnancy. Finally, we determined the predicted value of each marker determined before that pregnancy. All participating thrombophilic women received, based on the underlying disorder, prophylactic medication, either low molecular weight heparins and/or piridoxine and folic acid.

\section{METHODS}

\section{Selection of Patients}

A total of 350 formerly preeclamptic, nondiabetic women participated in this study. Data acquisition was initiated at least 5 months postpartum. Formerly preeclamptic women were recruited from our outpatient clinic at the postpartum followup. Preeclampsia (gestational), hypertension, and the syndrome of hemolysis, elevated liver enzymes, and low platelets (HELLP) were defined according to the criteria of the National High Blood Pressure Education Program Working Group Report on High Blood Pressure in Pregnancy. ${ }^{1} \mathrm{We}$ defined fetal growth restriction on the basis of the birth of a baby with a neonatal birth weight below the tenth centile according to Dutch centiles set by Kloosterman. Measurement of the 24-hour urinary sodium output on the day before the experiment was performed to estimate sodium intake. None of the participants used vitamin supplements or any other medication in the 2 weeks before measurement. Women on anti-

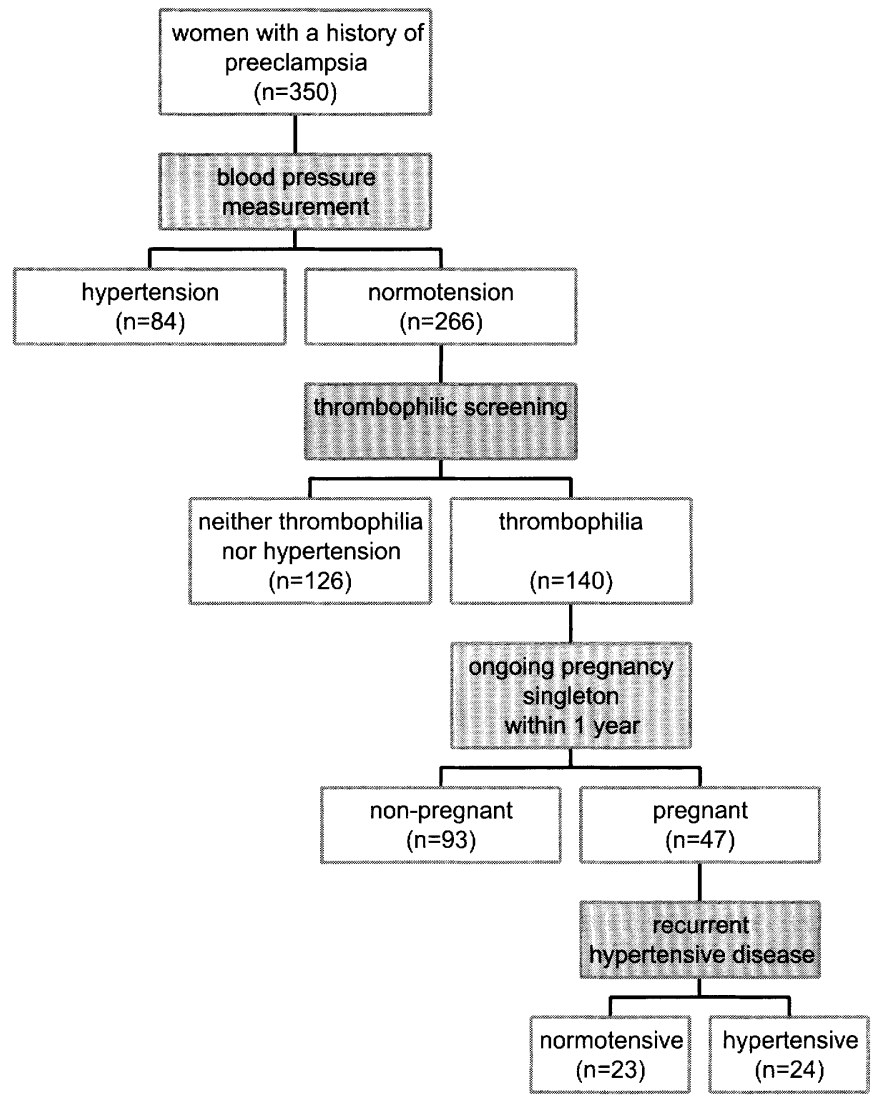

Figure 1. Management, subdivision, and treatment of formerly preeclamptic participants.

hypertensive drugs discontinued this medication at least 1 week prior to the study session. After an overnight fast, participants were tested for thrombophilia, and hemodynamic and metabolic function. Thrombophilia was defined as a condition characterized by the presence of at least one clotting disorder known to be associated with an increased risk of venous thromboembolism. Inclusion for final analysis required the establishment of an ongoing ( $>16$ weeks' gestational age) singleton pregnancy within 1 year after the pre-pregnant measurements in a normotensive thrombophilic formerly preeclamptic women. As a consequence, 47 formerly preeclamptic women could be included for final analysis. After the measurement sessions, formerly preeclamptic women were managed as illustrated in Figure 1. All subjects were Caucasian. Those who smoked refrained from smoking during pregnancy. All participants gave written informed consent. The hospital's medical ethical committee approved the study.

\section{Experimental Procedure}

The methodology of the measurements and calculations with respect to the thrombophilic screening and hemodynamic function have been detailed elsewhere. ${ }^{6}$

THROMBOPHILIC SCREENING. In short, we measured the presence of lupus anticoagulant and anticardiolipin antibodies. We defined the antiphospholipid syndrome as the condition where the titers of the circulating anticardiolipin antibodies were 
Table 1. Demographic Data From the Two Subgroups of Formerly Preeclamptic Women

\begin{tabular}{lcc}
\hline & $\begin{array}{c}\text { THROMB } \\
(\boldsymbol{n}=\mathbf{2 3})\end{array}$ & $\begin{array}{c}\text { COMPLITHROMB } \\
(\boldsymbol{n}=\mathbf{2 4})\end{array}$ \\
\hline Age $(\mathrm{y})$ & $29(24-35)$ & $28(16-34)$ \\
Height $(\mathrm{cm})$ & $170(154-183)$ & $170(157-180)$ \\
$\begin{array}{l}\text { Body mass index } \\
\quad\left(\mathrm{kg} \cdot \mathrm{m}^{-2}\right)\end{array}$ & $22(19-33)$ & $26(19-36)^{*}$ \\
Parity & $1(1-2)$ & $1(1-3)$ \\
$\begin{array}{l}\text { Sodium excretion } \\
\left(\mathrm{mmol} \cdot 24 \mathrm{~h}^{-1}\right)\end{array}$ & $107(39-166)$ & $125(67-297)$ \\
\hline
\end{tabular}

$* P<.05$.

higher than 15 GPL for IgG antiphospholipid antibodies and 20 MPL for IgM antiphospholipid antibodies. Coagulation tests were performed after a venous puncture. After elimination of platelets, samples were stored at $-80 \mathrm{C}$ prior to assay. In these samples we determined protein $\mathrm{C}$ activity, total protein $\mathrm{S}$ antigen and free protein $\mathrm{S}$, activated protein $\mathrm{C}$ resistance, and antithrombin activity. A methionine-loading test was used to diagnose hyperhomocysteinemia. During the test participants consumed a standard low-methionine breakfast and lunch.

MEASUREMENT OF CENTRAL HEMODYNAMIC FUNCTION. In the midfollicular phase (day $5 \pm 2$ ) of the menstrual period the measurement session started at 9 AM after sampling of the clotting variables. Participants did not drink caffeine- or alcohol-containing beverages and refrained from smoking and eating for at least 10 hours before the experiment. Throughout the measurement session, subjects were in halfsupine position on a comfortable chair. Arterial blood pressure and heart rate were recorded intermittently by a semiautomatic oscillometric device (Dinamap Vital Signs Monitor 1846; Critikon, Tampa, FL), interrupted only during blood sampling. Urinary sodium concentration was measured in a urine sample collected over the 24 hours preceding the measurement session. All variables were measured by standard chemical procedures.

MEASUREMENT OF PLASMA VOLUME. Plasma volume was measured using the iodine 125 -albumin $\left({ }^{125} \mathrm{I}-\mathrm{HSA}\right)$ indicator dilution method and expressed in milliliters per kilogram $(\mathrm{mL} / \mathrm{kg})$ lean body mass $(\mathrm{LBM}){ }^{6}$

ECHOCARDIOGRAPHY. Echocardiography (ECG) to assess cardiac function was performed in the semi-left lateral position, after completion of the plasma volume measurement and after 5 minutes rest, using a cross-sectional, phased-array ECG Doppler system (Hewlett-Packard Sonos 2500, Andover, MA. $^{6}$

Cardiac output $\left(\mathrm{L} \cdot \mathrm{min}^{-1}\right)$ was calculated by multiplying stroke volume $(\mathrm{mL})$ and heart rate $(\mathrm{bpm})$. In this formula, heart rate was obtained by taking the reciprocal of the mean of five consecutive R-R intervals on the ECG. Stroke volume was calculated by multiplying the aortic velocity integral and the aortic area. Aortic flow was measured across the aortic valves from an apical approach. ${ }^{6}$ Total peripheral vascular resistance (dyne $\cdot \mathrm{s} \cdot \mathrm{cm}^{-5}$ ) and index (dyne $\cdot \mathrm{s} \cdot \mathrm{cm}^{-5} \cdot \mathrm{m}^{-2}$ ) were obtained by taking the quotient, respectively, of mean arterial pressure and cardiac output and cardiac index. The values used for mean arterial pressure were obtained during the cardiac output measurement using the recordings of the Dinamap apparatus and were calculated as the mean of three consecutive recordings.

STATISTICAL ANALYSIS. Data are presented as medians and ranges unless stated otherwise. Intragroup differences were tested with the Wilcoxon signed-ranks matched-pairs test, and differences between groups with the Mann-Whitney $U$ test. Correlations, when calculated, between concomitantly measured potentially related variables, were tested by Spearman rank correlation analysis. A $P$ value less than .05 was considered statistically significant. We performed a multivariate backward stepwise logistic regression analysis that included as dependent variables only those that were found to be correlated between the recurrence of gestational hypertension and preeclampsia, and maternal hemodynamic variables. This analysis allowed us to identify actual independent predictors of maternal hypertensive complications. From the independent predictors, we calculated the Mantel-Haenszel common odds ratio and 95\% confidence interval. Finally, the calculated minimum detectable differences of the mean of variables within the thrombophilic group ( $n=47, \alpha=0.05, \beta=0.10$ ), assuming a normal distribution of the data, were $11 \%$ for body mass index, $6 \%$ for mean arterial pressure, $8 \%$ for heart rate, $9 \%$ for plasma volume, $11 \%$ for cardiac output, $9 \%$ for cardiac index, $11 \%$ for total peripheral vascular resistance and its index, 3 weeks in gestational age at delivery, $595 \mathrm{~g}$ in birth weight, and a difference of 15 in centile, respectively.

\section{RESULTS}

Of the 350 eligible formerly preeclamptic participants, 47 normotensive thrombophilic formerly preeclamptic women were available for final analysis. Thirty-eight thrombophilic formerly preeclamptic women had one thrombophilic disorder, and nine had more than one. Twenty-four of 47 developed at least gestational hypertension. They were assigned to

Table 2. Hemodynamic and Vascular Data

\begin{tabular}{|c|c|c|}
\hline & $\begin{array}{c}\text { THROMB } \\
(n=23)\end{array}$ & $\begin{array}{c}\text { COMPLITHROMB } \\
(n=24)\end{array}$ \\
\hline $\begin{array}{l}\text { Mean arterial pressure } \\
(\mathrm{mmHg})\end{array}$ & $87(72-97)$ & $86(77-101)$ \\
\hline Heart rate $(\mathrm{bpm})$ & $67(44-87)$ & $62(48-83)$ \\
\hline $\begin{array}{l}\text { Cardiac output } \\
\left(\mathrm{L} \cdot \min ^{-1}\right)\end{array}$ & $5.3(4.1-8.2)$ & $5.4(3.9-6.9)$ \\
\hline $\begin{array}{l}\text { Cardiac index } \\
\quad\left(\mathrm{L} \cdot \min ^{-1} \cdot \mathrm{m}^{-2}\right)\end{array}$ & $3.2(2.6-4.3)$ & $2.9(2.2-3.4)^{*}$ \\
\hline $\begin{array}{l}\text { TPVR } \\
\quad\left(\times 10^{2} \text { dyne } \cdot \mathrm{s} \cdot \mathrm{cm}^{-5}\right) \\
\text { TPVR index }\left(\times 10^{2} \text { dyne }\right.\end{array}$ & $13(8-16)$ & $14(10-17)$ \\
\hline$\left.\cdot \mathrm{s} \cdot \mathrm{cm}^{-5} \cdot \mathrm{m}^{-2}\right)$ & $21(13-27)$ & $25(19-31)^{*}$ \\
\hline $\begin{array}{l}\text { Plasma volume } \\
\left(\mathrm{mL} \cdot \mathrm{kg}_{\mathrm{LBM}}{ }^{-1}\right)\end{array}$ & $53(43-59)$ & $45(25-54)^{*}$ \\
\hline
\end{tabular}

TPVR $=$ total peripheral vascular resistance.

$* P<.05$. 
Table 3. Maternal Pregnancy Outcome

\begin{tabular}{|c|c|c|c|}
\hline & Group & $\begin{array}{c}\text { Previous } \\
\text { pregnancy } n(\%)\end{array}$ & $\begin{array}{c}\text { Current } \\
\text { pregnancy } n(\%)\end{array}$ \\
\hline \multirow[t]{2}{*}{ Gestational hypertension } & THROMB & $23(100 \%)$ & $0(0 \%)^{*}$ \\
\hline & COMPLITHROM & $24(100 \%)$ & $24(100 \%)$ \\
\hline \multirow[t]{2}{*}{ Preeclampsia } & THROMB & $23(100 \%)$ & $0(0 \%)^{*}$ \\
\hline & COMPLITHROM & $24(100 \%)$ & $12(50 \%)^{*} \uparrow$ \\
\hline \multirow{2}{*}{ HELLP syndrome } & THROMB & $14(61 \%)$ & $0(0 \%)^{*}$ \\
\hline & COMPLITHROM & $12(50 \%)$ & $12(50 \%) \uparrow$ \\
\hline \multirow[t]{2}{*}{ Gestational age PE/HELLP (wk) } & THROMB & $29(22-39)$ & - \\
\hline & COMPLITHROM & $28(23-38)$ & $36(21-39)^{*}$ \\
\hline
\end{tabular}

An arrow indicates a difference between both groups.

HELLP syndrome $=$ hemolysis, elevated liver enzymes, low platelets; $\mathrm{PE}=$ preeclampsia.

* Indicates the value is different from the previous pregnancy within the same subgroup $(P<.05)$.

the COMPLITHROMB group. Those who remained normotensive throughout pregnancy were assigned to the THROMB group. The demographic characteristics of included participants are listed in Table 1. The two subgroups of normotensive thrombophilic formerly preeclamptic women and the controls were comparable with respect to age, height, parity, and urinary sodium output. COMPLITHROMB were more obese than THROMB.

Among the formerly preeclamptic women, the antiphospholipid syndrome $(13 / 47,28 \%)$ and hyperhomocysteinemia $(24 / 47,51 \%)$ were most common, followed by protein $\mathrm{S}$ deficiency $(11 / 47,23 \%)$, activated protein $\mathrm{C}$ resistance as a consequence of factor $\mathrm{V}$ Leiden mutation $(6 / 47,13 \%)$ and protein $\mathrm{C}$ deficiency $(1 / 47,2 \%)$. Nine formerly preeclamptic women, who were diagnosed as having the antiphospholipid syndrome, were IgG serotypes. We did identify one woman with antithrombin deficiency. Between evaluation and subsequent ongoing pregnancy, 10 of 47 (21\%) formerly preeclamptic thrombophilic women experienced a spontaneous abortion, six in conjunction with hyperhomocysteinemia (one with an antiphospholipid syndrome as well), two in conjunction with protein S deficiency, and two with an antiphospholipid syndrome. There were no differences between type of thrombophilic disorder and the recurrence of hypertensive complications.
Table 2 lists the cardiovascular data and plasma volume. In COMPLITHROMB, total peripheral vascular resistance index was higher, and plasma volume and cardiac index lower, than in THROMB.

Maternal and fetal data with respect to the preceding and subsequent pregnancies are listed in Tables 3 and 4, respectively. Most of the outcome variables in the two formerly preeclamptic subgroups had improved markedly in the subsequent pregnancy relative to the preceding pregnancy. Nonetheless, COMPLITHROMB had a higher incidence of fetal growth restriction as indicated by lower birth weight and centile. In the whole group, as compared to the preceding complicated pregnancy, we noted a 7 -week (0 to 15$)$ prolongation of pregnancy, which contributed to an increase in neonatal weight by $1880 \mathrm{~g}(-220$ to 3210$)$ corresponding with an increase in birth weight centile $12(-45$ to 88$)$. If in these formerly preeclamptic women the subsequent pregnancy was complicated by recurrent preeclampsia, the complication developed approximately 7 weeks ( -5 to 14 ) later than in the preceding index pregnancy. Pre-pregnant plasma volume correlated inversely with the recurrence rate of gestational hypertension $(r=-0.67, P<.0001)$, preeclampsia $(r=-0.64$, $P<.0001)$, and HELLP syndrome $(r=-0.37, P=.01)$. In addition, a low plasma volume predisposed to a lower gestational age at delivery $(r=-0.31, P=.04)$. A receiver

Table 4. Fetal Pregnancy Outcome

\begin{tabular}{|c|c|c|c|}
\hline & Group & $\begin{array}{c}\text { Previous } \\
\text { pregnancy } n(\%)\end{array}$ & $\begin{array}{c}\text { Current } \\
\text { pregnancy } n(\%)\end{array}$ \\
\hline Gestational age at delivery (wk) & THROMB & $31(24-39)$ & $39(35-41)^{*}$ \\
\hline \multirow[t]{2}{*}{ Prematurity } & THROMB & $19(82 \%)$ & $1(4 \%)^{*}$ \\
\hline & COMPLITHROMB & $22(92 \%)$ & $5(21 \%)^{*} \uparrow$ \\
\hline Birth weight (g) & THROMB & $1170(195-3260)$ & $3440(2330-4240)^{*}$ \\
\hline Centile & COMPLITHROMB & $5(1-90) \downarrow$ & $25(2-96)^{*} \downarrow$ \\
\hline \multirow[t]{2}{*}{ Fetal growth Restriction } & THROMB & $6(26 \%)$ & $5(22 \%)$ \\
\hline & COMPLITHROMB & $14(58 \%) \uparrow$ & $6(25 \%)^{*}$ \\
\hline \multirow[t]{2}{*}{ Stillbirth } & THROMB & $5(22 \%)$ & $0(0 \%)^{*}$ \\
\hline & COMPLITHROMB & $6(25 \%)$ & $0(0 \%)^{*}$ \\
\hline
\end{tabular}

An arrow indicates a difference between both groups.

* Indicates the value is different from the previous pregnancy within the same subgroup $(P<.05)$. 


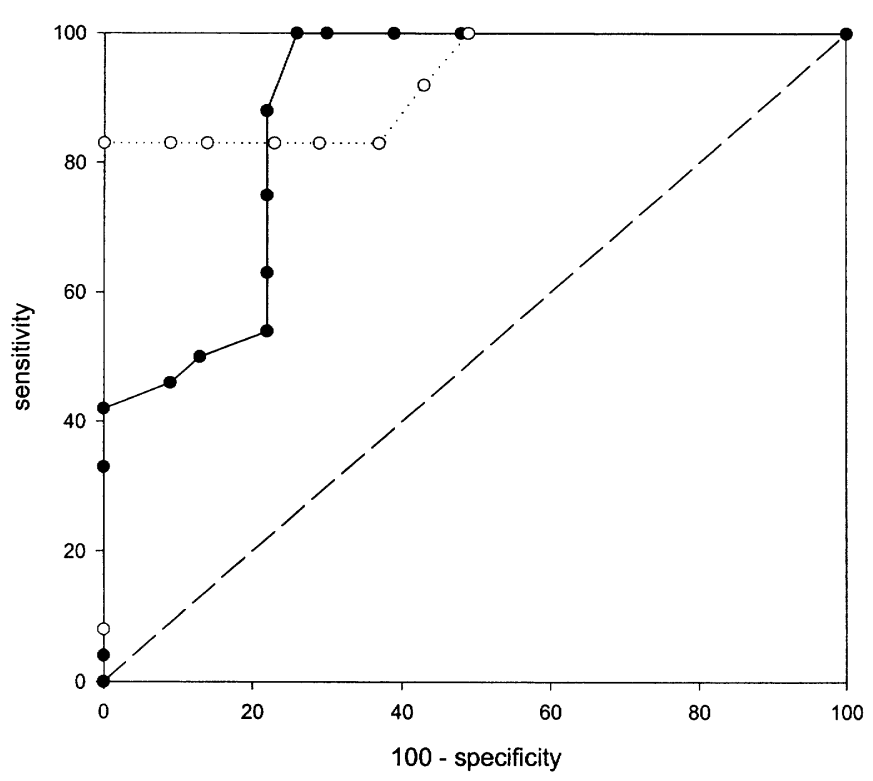

Figure 2. Receiver operating characteristic curve for both gestational hypertension $(\mathrm{GH})$ (solid line, solid circles) and preeclampsia (PE) (dotted line, open circles) as a function of plasma volume among thrombophilic formerly preeclamptic women. ${ }^{*} \mathrm{GH}: \mathrm{PV} \leq 49 \mathrm{~mL} \cdot \mathrm{kg}$ $\mathrm{LBM}^{-1}$; sensitivity $=100 \%$, specificity $=74 \%$, positive predictive value $=80 \%$, negative predictive value $=100 \%$. ${ }^{*} \mathrm{PE}: \mathrm{PV} \leq 42 \mathrm{~mL}$ $\cdot \mathrm{kg} \mathrm{LBM}{ }^{-1}$ : sensitivity $=83 \%$, specificity $=100 \%$, positive predictive value $=100 \%$, negative predictive value $=95 \%$.

operating characteristic (ROC) curve to explore the predictive potential of the pre-pregnant plasma volume measurements indicated that normotensive thrombophilic formerly preeclamptic participants with a plasma volume below $42 \mathrm{~mL} \cdot \mathrm{kg}$ $\mathrm{LBM}^{-1}$ were at high risk to develop recurrence of preeclampsia in a subsequent pregnancy, with a sensitivity and specificity of $83 \%$ and $100 \%$, respectively. The associated positive and negative predictive values were $100 \%$ and $95 \%$, respectively (Figure 2). Almost $80 \%$ of this population (37/47) had a plasma volume of at least $42 \mathrm{~mL} \cdot \mathrm{kg} \mathrm{LBM}^{-1}$. Two of these women $(5 \%)$ developed recurrent preeclampsia. Both women were suffering from the antiphospholipid syndrome. Nonetheless, over the whole population, there was no correlation between the type of thrombophilia and pregnancy outcome. A plasma volume below $49 \mathrm{~mL} \cdot \mathrm{kg} \mathrm{LBM}^{-1}$ identified thrombophilic women destined to develop gestational hypertension with a sensitivity and specificity of $100 \%$ and $74 \%$, and positive and negative predictive values of $80 \%$ and $100 \%$, respectively (Figure 2). In addition, we performed a multivariate backward logistic regression analysis in which body mass index, plasma volume, cardiac index, and total peripheral vascular resistance index were included. After analysis, for recurrent gestational hypertension, plasma volume $(P=.002)$ and total peripheral vascular resistance index $(P=.047)$ appeared to be independent risk factors, while in recurrent preeclampsia, only plasma volume remained an independent variable $(P=.002)$. From the multivariate analysis, a regression score was computed, after which a formula was constructed to predict recurrent hypertensive complications. Comparing the predicted hypertensive problems as a function of observed hypertensive complications, total peripheral vascular resistance did not contribute to better predictive power. Therefore, only plasma volume was used to compute recurrence risks. The common odds ratio on hypertensive complications varied as a function of plasma volume (Table 5).

The chance to develop recurrent gestational hypertension can be calculated according to the formula: $\mathrm{p}_{\text {gestational hypertension }}$ $=1 / 1+\mathrm{e}^{-\left(15.967-0.33 \mathrm{PV}_{\text {LBM }}\right)}$. The chance to develop recurrent preeclampsia can be calculated according to the formula: $\mathrm{p}_{\text {preeclampsia }}=1 / 1+\mathrm{e}^{-\left(23.551-0.547 \mathrm{PV}_{\text {LBM }}\right)}$.

\section{DISCUSSION}

Although the underlying pathogenetic mechanisms of preeclampsia are still unclear, there is general agreement about a central role for throphoblastic factors and dysfunctional endothelium in triggering the typical clinical symptoms. ${ }^{9}$ Trophoblastic and endothelial function can be jeopardized by numerous factors, either biochemically, such as in thrombophilia or diabetes mellitus, or mechanically, such as in hypertension. Normal pregnancy is associated with a physiologic rise in the strain exerted on the endothelium. Therefore, it is not surprising that accompanying risk factors enhance the development of vascular complications during pregnancy. In this prospective study, preexistent maternal features with extra endothelial strain as common denominator were found to predispose for recurrent hypertensive disorders in high-risk pregnancies.

With respect to the demographic characteristics, except for a higher body mass index in the COMPLITHROMB group, the two formerly preeclamptic subgroups did not differ appreciably. A higher body mass index in formerly preeclamptic women has also been reported by others and is a well-known risk factor for both cardiovascular and metabolic complications. ${ }^{12}$ There is substantial variation in reported incidences of thrombophilia among formerly preeclamptic women among different geographic regions in the world. However, the increased incidence of thrombophilic disorders among the formerly preeclamptic individuals in this study is in line with previous findings in Israeli and Dutch populations. ${ }^{3-5}$

Most previous studies on recurrence of hypertensive disorders in pregnancy are based on obstetrical history as a starting point, rather than underlying disorders. Furthermore, most of these studies were performed retrospectively, in untreated

Table 5. Risk of Recurrent Hypertensive Complications as a Function of Plasma Volume

\begin{tabular}{lcl}
\hline \multicolumn{1}{c}{ Plasma volume } & OR & 95\% CI \\
\hline Gestational hypertension & & \\
Plasma volume $>49 \mathrm{~mL} \cdot \mathrm{kg}_{\mathrm{LBM}}{ }^{-1}$ & 1 & Reference \\
$\mathrm{PV} \leq 49 \mathrm{~mL} \cdot \mathrm{kg}_{\mathrm{LBM}}{ }_{-1}$ & 32.6 & $5.8-181.7$ \\
$\mathrm{PV} \leq 44 \mathrm{~mL} \cdot \mathrm{kg}_{\mathrm{LBM}}$ & 34.0 & $4.9-235.6$ \\
Preeclampsia & & \\
Plasma volume $>49 \mathrm{~mL} \cdot \mathrm{kg}_{\mathrm{LBM}}{ }^{-1}$ & 1 & Reference \\
$\mathrm{PV} \leq 49 \mathrm{~mL} \cdot \mathrm{kg}_{\mathrm{LBM}}{ }_{-1}^{-1}$ & 11.0 & $1.3-94.3$ \\
$\mathrm{PV} \leq 44 \mathrm{~mL} \cdot \mathrm{kg}_{\mathrm{LBM}}$ & 36.0 & $3.7-352.6$ \\
\hline
\end{tabular}

$\mathrm{OR}=$ odds ratio $; \mathrm{CI}=$ confidence interval $; \mathrm{PV}=$ plasma volume . 
women, and in a different geographically localized population. Nevertheless, among normotensive formerly preeclamptic women, the reported recurrence rate of preeclampsia in a subsequent pregnancy ranged from $32-55 \% .{ }^{13-15}$ Normotensive women with a history of HELLP syndrome had recurrent preeclampsia and HELLP syndrome in $19-23 \%$ and $3-27 \%$, respectively. ${ }^{16,17}$ In addition, with respect to gestational age, subsequent HELLP pregnancies lasted on the average 2 weeks longer than the preceding pregnancy. ${ }^{16}$ In our study, both preeclampsia and HELLP syndrome recurred in $26 \%$ of the formerly preeclamptic participants. However, clinically it is important to consider this recurrence rate in the context of a milder course of the recurrent disease as indicated by its later onset and the substantially higher birth weight and corresponding birth weight centile.

In thrombophilic formerly preeclamptic women, the recurrence rate of vascular complications was closely linked to a low plasma volume, the most characteristic feature of a (latent) hypertensive hemodynamic phenotype. 6 More explicitly, if plasma volume exceeded $49 \mathrm{~mL} / \mathrm{kg} \mathrm{LBM}$, which was the case in $34 \%$ of the normotensive thrombophilic formerly preeclamptic population, preeclampsia and HELLP syndrome did not recur. Plasma volume seems to provide an index of cardiovascular adaptive capacity. Low values for this parameter may therefore indicate a diminished capacity to meet the increased blood flow demands of pregnancy, which, in some cases, can be expected to lead to hemodynamic maladaptation and with it the development of hypertensive complications and fetal growth restriction.

The present study was not designed to prove the efficacy of low molecular weight heparin and/or vitamin supplementation in reducing the recurrence risk of hypertensive complications in pregnancy in formerly preeclamptic women with a thrombophilic phenotype. Nevertheless, in thrombophilic formerly preeclamptic women, recurrent gestational hypertension, preeclampsia, HELLP syndrome, and growth restriction seem to be related to the latent hypertensive profile rather than the underlying thrombophilia. Therefore, our data indicate that a prospective randomized study designed to evaluate the efficacy of this prophylactic regimen might benefit from the consideration that concomitantly reduced vascular reserves can interfere with the study results. The results of the present study suggest that insight into the hemodynamic and clotting functions add an extra dimension to the counseling of women with a history of severe vascular complications in a preceding pregnancy.

In conclusion, pre-pregnant hemodynamic and hemostatic variables in formerly preeclamptic women predict recurrent hypertensive complications in a subsequent pregnancy.

\section{REFERENCES}

1. Report of the National High Blood Pressure Education Program Working Group on High Blood Pressure in Pregnancy. Am J Obstet Gynecol 2000;183:S1-22.

2. Schuitemaker NEWvan Roosmalen J, Dekker GA, van Dongen PWJ, van Geijn HP, Bennebroek Gravenhorst J. Confidential inquiry into maternal deaths in The Netherlands 1983-1992. Eur J Obstet Gynecol Reprod Biol 1998;79:57-62.

3. Dekker GA, de Vries JIP, Doelitzsch PM, et al. Underlying disorders associated with severe early-onset preeclampsia. Am J Obstet Gynecol 1995;173:1042-8.

4. van Pampus MG, Dekker GA, Wolf $\mathrm{H}$, et al. High prevalence of hemostatic abnormalities in women with a history of severe preeclampsia. Am J Obstet Gynecol 1999;180:1146-50.

5. Kupferminc MJ, Eldor A, Steinman N, et al. Increased frequency of genetic thrombophilia in women with complications of pregnancy. N Engl J Med 1999;340:9-13.

6. Spaanderman MEA, Ekhart THA, van Eyck J, Cheriex EC, de Leeuw PW, Peeters LLH. Asymptomatic ex-preeclamptic women have latent hemodynamic abnormalities. Am J Obstet Gynecol 2000;182:101-7.

7. van Beek E, Ekhart THA, Schiffers PMH, van Eyck J, Peeters LLH, de Leeuw PW. Persistent abnormalities in volume homeostasis and renal hemodynamics in patients with a history of preeclampsia. Am J Obstet Gynecol 1998;179:690-6.

8. Aardenburg R, Spaanderman MEA, Ekhart THA, van Eijndhoven HW, van der Heijden OWH, Peeters LLH. Low plasma volume following pregnancy complicated by pre-eclampsia predisposes for hypertensive disease in a-next pregnancy. BJOG 2003;110:1001-6.

9. Roberts JM. Endothelial dysfunction in preeclampsia. Semin Reprod Endocrinol 1998;16:5-15.

10. Walker FM, Ferguson SE, Allen VM. Heparin for pregnant women with acquired or inherited thrombophilias (Cochrane Review). The Cochrane Library, Vol 2. Chichester, UK: Wiley, 2004.

11. Brenner B, Kupferminc MJ. Inherited thrombophilia and poor pregnancy outcome. Best Pract Res Clin Obstet Gynaecol 2003;17:427-39.

12. Eskenazi B, Fenster L, Sidney S. A multivariate analysis of risk factors for preeclampsia. JAMA 1991;266:237-41.

13. Sibai BM, el-Nazer A, Gonzalez-Ruiz A. Severe preeclampsiaeclampsia in young primigravid women: Subsequent pregnancy outcome and remote prognosis. Am J Obstet Gynecol 1986;155:1011-6.

14. Sibai BM, Mercer B, Sarinoglu C. Severe preeclampsia in the second trimester: Recurrence risk and long-term prognosis. Am J Obstet Gynecol 1991;165:1408-12.

15. Zhang J, Troendle J, Levine R. Risks of hypertensive disorders in the second pregnancy. Paediatr Perinat Epidemiol 2001;15:22631.

16. Sullivan CA, Magnann EF, Perry KG Jr, Roberts WE, Blake PG, Martin JN Jr. The recurrence risk of the syndrome of hemolysis, elevated liver enzymes, and low platelets (HELLP) in subsequent gestations. Am J Obstet Gynecol 1994;171:940-3.

17. Sibai BM, Ramadan MK, Chari RS, Friedman SA. Pregnancies complicated by HELLP syndrome (hemolysis, elevated liver enzymes, and low platelets): Subsequent pregnancy outcome and long-term prognosis. Am J Obstet Gynecol 1995;172:125-9. 